\title{
Editorial for EAIT Issue 1, 2017
}

\author{
Arthur Tatnall ${ }^{1}$
}

Published online: 26 December 2016

(C) Springer Science+Business Media New York 2016

Before beginning to describe the content of this issue of EAIT let me introduce an exciting new Springer publication for which we invite your contribution in 2017: Encyclopaedia of Education and Information Systems.

The scope of the encyclopaedia will be large, covering all aspects of the interaction between Education and Information Technologies. It will include IT and Education in kindergartens, primary and secondary schools, universities, training colleges, industry training, distance education and further education. It will cover all aspects of IT and education including:

- Teaching about computing: hardware, software, systems analysis, systems design, uses of computers, social aspects of ICT use and so on

- The use of ICT to aid teaching and understanding in many other subject areas: tools (such as word processing, databases and spreadsheets), simulations, educational games, computer assisted learning etc.

- Use of technologies such as iPads, interactive whiteboards and robotics

- Use of computers to aid in educational administration

- National policies of IT and Education.

The aim of producing this encyclopaedia is to offer scholars (and the general public) an indication of the breadth and importance of this topic. It will be to show the many ways in which IT is being used, and could be used, in Education.

I encourage all those reading this journal, as well as those writing for EAIT to make a contribution to the encyclopaedia. Further details of what is required and how to go about submission will be available on the website soon.

The first article in this issue: "Developing collective learning extension for rapidly evolving information system courses" is by Nitin Agarwal and Faysal Ahmed (University of Arkansas at Little Rock, USA) who point out that due to rapidly evolving

Arthur Tatnall

Arthur.Tatnall@vu.edu.au

1 Victoria University, PO Box 14428, Melbourne 8001, Australia 
Information System technologies, instructors find themselves stuck in the constant game of catching up, and students also find their skills obsolete almost as soon as they graduate. The article describes how the authors developed a collective learning extension leveraging social media and implemented it in three IS courses at the University of Arkansas at Little Rock.

Rachel Menzies and Karen Petrie (University of Dundee, Scotland) and Mark Zarb (Robert Gordon University, Aberdeen, Scotland) next write on: "A case study of Facebook use: Outlining a multi-layer strategy for higher education". They note that many students are looking to appropriate social networking sites, amongst them Facebook, to enhance their learning experience, and a growing body of literature reports on the motivation of students and staff to engage with this as a learning platform as well as mapping such activities to pedagogy and curricula.

"Clickers and formative feedback at university lectures" by Kjetil Egelandsdal and Rune Johan Krumsvik (University of Bergen, Norway) suggests that lecturing is often criticised for being a monological and student passive way of teaching, but that digital technology, such as Student Response Systems, can be used to reconstruct the traditional lecturing format. Their findings show that most students experienced receiving formative feedback supporting their self-monitoring from the interventions described.

Following this, an article by Simin Ghavifekr and Hazline Mahmood (University of Malaya): "Factors affecting use of an e-learning platform (SPeCTRUM) among University students in Malaysia" deals with e-learning in Malaysia. e-learning was pioneered by private universities and has since been adopted in most other universities. In the setting of a research university in Kuala Lumpur, a quantitative design was conducted to investigate the factors affecting the usage of e-Learning platform SPeCTRUM by the students.

Female student representation in tertiary education in Computing and Science, Technology, Engineering and Mathematics (STEM) is under-researched in a number of countries including Greece. This article: "Computing and STEM in Greece: Gender representation of students and teachers during the decade 2002/2012" by Maria Kordaki and Ioannis Berdousis focuses on the investigation of gender representation of tertiary-level education students and of secondary level education teachers in Computing and STEM education in Greece.

"Android based mobile apps for information security hands-on education" notes that as mobile devices grow increasingly in popularity within the student community, novel educational activities and tools, as well as learning approaches can be developed to get benefit from this prevalence of mobile devices. This article was contributed by Zouheir Trabelsi, Mohammed Al Matrooshi, Saeed Al Bairaq, Walid Ibrahim and Mohammad M. Masud (UAE University, Al Maquam).

Stelios Xinogalos, Maya Satratzemi and Christos Malliarakis (University of Macedonia, Thessaloniki, Greece) then contribute: "Microworlds, games, animations, mobile apps, puzzle editors and more: What is important for an introductory programming environment?" They point out that teaching and learning programming constitutes a challenge and although several teaching approaches and programming tools have been proposed, it seems that they have limited impact on classroom practice. Their article investigates students' perceptions on five educational programming environments that are widely used and the features that they claim any introductory programming environment should have. 
The next article: "Impact of MOODLE platform on the pedagogy of students and staff: Cross-curricular comparison" is by Emerson Abraham Jackson (Chartered Institute of Foresters, Edinburgh, UK). This research paper explored the importance of MOODLE learning platform, its contribution in promoting flexible teaching and the need for supported action to assist teachers and tutors develop differentiated learning resources with the dual purpose of improving flexibility in learning and assessment outcomes for students.

"Assessing the impact of technology based digital equalizer programme on improving student learning outcomes" by Subrata Sarkar (Digital Equalizer (DE) American India Foundation), Sanjay Mohapatra (Xavier Institute of Management, Bhubaneswar, India) and J. Sundarakrishnan (Digital Equalizer (DE) American India Foundation) describes research to assess the impact of the Digital Equalizer program in terms of learning outcomes of students in subjects like science, mathematics and geography after eight months of implementing this program in 283 schools across 30 districts of Odisha, India.

The purpose of the study reported on in the next paper was to design and test multimedia for deaf and hard of hearing learners. "The design and testing of multimedia for teaching arithmetic to deaf learners" was contributed by Piyaporn Techaraungrong, Surachai Suksakulchai and Wacheerapan Kaewprapan (King Mongkut's University of Technology Thonburi, Thailand) and Elizabeth Murphy (Memorial University of Newfoundland, Canada). The study focused on counting, addition and subtraction with grade one (age 7) deaf and hard of hearing learners in Thailand using specially created multimedia, informed by design considerations for these learners of arithmetic and aimed to minimise cognitive load.

"Global prevalence of sleep deprivation in students and heavy media use" describes a topic of considerable concern today. Meilan Zhang, Daniel A. Tillman and Song A. An (University of Texas at El Paso, USA) describe how the two latest international educational assessments found global prevalence of sleep deprivation in students, consistent with what has been reported in sleep research, but that despite the fundamental role of adequate sleep in cognitive and social functioning, this important issue has been largely overlooked by educational researchers.

"Social teaching: Student perspectives on the inclusion of social media in higher education" by Samantha Cooke (University of Surrey, UK) notes that traditional teaching methodologies employed within universities, comprising of lectures and seminars, have come to be scrutinised for their impersonal approach and social media and networking sites have become increasingly popular as learning and teaching resources in higher education, providing students with increased opportunities for educational engagement.

Souvik Sengupta (Bengal Institute of Technology) and Ranjan Dasgupta (National Institute of Technical Training and Research, Kolkata, India) then write on an approach for architectural design of a Learning Management System (LMS), which is verifiable against the Learning Technology System Architecture (LTSA) conformance rules. Their article: "Architectural design of a LMS with LTSA-conformance" introduces a new method for software architectural design that extends the Unified Modelling Language (UML) component diagram with the formal architectural style of Acme, hence, combines the advantages of the visual appeal of a graphical method and preciseness of a formal method. 
"Considering learning styles and context-awareness for mobile adaptive learning" by Richard A. W. Tortorella (University of Eastern Finland) and Sabine Graf (Athabasca University, Edmonton, Canada) deals with the educational significance of mobile devices. In order to get the most out of the portable computing power present at students' fingertips, this paper proposes an approach for providing mobile, personalized course content tailored to each individual's learning style while incorporating adaptive context awareness.

The next article deals with issues of digital technology use at the interface of formal and informal learning contexts and is by Susanna Pöntinen, Patrick Dillon and Pertti Väisänen (University of Eastern Finland): "Student teachers' discourse about digital technologies and transitions between formal and informal learning contexts". The research found that resources and obstacles associated with transitions between formal and informal learning contexts are concerned with students' engagement in linking formal and informal activities, avoiding uncertainty and participating in shared work practices.

Aditya Khamparia and Babita Pandey (Lovely Professional University, Punjab, India) next write on: "A novel method of case representation and retrieval in CBR for e-learning". Their paper discusses a novel method developed for representation and retrieval of cases in case based reasoning (CBR) as a part of an elearning system which is based on various student features. Their approach integrated Artificial Neural Networks (ANN) with Data mining (DM) and CBR.

"Pedagogy and interactive white board technology integration in higher education institutions: Computer-based teaching scenario prototypes" describes research by Nabeel Al-Qirim, Ahlam Mesmari, Khawlah Mazroeei, Shamma Khatri and Zuwainah Kaabi (United Arab Emirates University, Al Ain, UAE). This research investigated issues impacting Interactive White Board Technology adoption and use in a higher education institution.

Pat Reid (University of Cincinnati, USA) next writes on: "Supporting instructors in overcoming self-efficacy and background barriers to adoption". Among the barriers to instructional technology adoption are faculty self-efficacy (a faculty member's belief or confidence in their ability to succeed) and background (including the instructor's previous experiences). Faculty adoption of instructional technology is not a straightforward 'provide it and they will come' scenario and this article investigates five categories of barriers to adoption.

Jaana-Maija Koivisto and Hannele Niemi (University of Helsinki), Jari Multisilta (Tampere University of Technology) and Elina Eriksson (University of Turku, Finland) argue that the growing use of game-based simulation in healthcare education reflects the opportunities afforded to learners by serious games, which simulate real-world situations and enable students to emulate the roles of healthcare professionals in a safe and engaging learning environment. "Nursing students' experiential learning processes using an online $3 D$ simulation game" presents a study that applied Kolb's experiential learning theory to investigate nursing students' experiential learning processes during a 3D simulation game.

The final article in this issue: "The use of lecture recordings in higher education: A review of institutional, student, and lecturer issues" is by Frances V. O'Callaghan, David L. Neumann, Liz Jones and Peter A. Creed (Griffith University, Gold Coast, Australia). This article examined the literature on lecture recordings for on-campus 
courses from the perspective of students, lecturers, and the institution. They conclude that the positives of lecture recordings outweigh the negatives and its continued use in higher education is recommended.

Just to reiterate, please keep your eyes open for your opportunity to make a contribution to the Encyclopaedia of Education and Information Systems. Details of what sort of articles are required and how to submit them will be available soon.

Arthur Tatnall

Editor-in-Chief 